\title{
Comparison of methods for sampling saproxylic beetles in fine wood
}

\author{
Mats Jonsell \& Jesper Hansson
}

Jonsell, M. \& Hansson, J. 2007: Comparison of methods for sampling saproxylic beetles in fine wood. - Entomol. Fennica 18: 232-241.

Three methods for extracting saproxylic beetles from wood samples were compared. The aim with the samples was to collect substrate-specific data on the beetle fauna in different types of small diameter wood. The methods were: (1) sifting - peeling bark from the wood, sifting it and extracting beetles in Tullgren funnels, (2) box-rearing - storing wood in dark wooden boxes and using light to attract emerging beetles; and (3) sack-rearing - hanging the wood in white cotton sacks with a collection vial at the bottom. Rearing sacks gave the species richest samples. Box-rearing gave similar results, but some small beetle species, especially Staphylinidae, were less frequent. Sifting was not useful for species occurring as larvae in the wood, but gave results similar to the two rearing methods for most species that occurred as adults, and was the most efficient method for the Staphylinidae. The two rearing methods were somewhat more labour intensive than sifting, but produced more beetles per sample. Sack-rearing was somewhat more efficient than box-rearing.

M. Jonsell \& J. Hansson, Dept. of Entomology, SLU, Box 7044, SE-750 07 Uppsala, Sweden; corresponding author's e-mail: mats.jonsell@entom.slu.se

Received 11 September 2006, accepted 24 April 2007

\section{Introduction}

The majority of European forests are managed for timber production (Peterken 1996), therefore many saproxylic organisms are threatened since management practices have decreased the amount of dead wood available to them (Siitonen 2001). The threatened species are mainly associated with coarse wood (Jonsell et al. 1998, Grove 2002). However, due to the increasing costs of fossil fuels and problems with greenhouse gases, bioenergy in the form of forest fuel is becoming increasingly attractive to meet our energy needs. The main source is logging residues that until recently were retained on clear cut sites (Egnell et al. 2001). The increased use of these residues de- crease the availability of fine wood, which might in turn affect saproxylic species, not least because the sun-exposed position of the wood on clear cuts is beneficial to many saproxylic beetles (Lindhe et al. 2005). However, there is currently little information available regarding which species use these fine-wood fractions.

In order to investigate the saproxylic beetle fauna in logging residues we initiated a sampling program on clear cuts in southern Sweden. Our aim was to study substrate specific differences, i.e. differences between tree species and between diameter classes of logging residues. We therefore discarded the widely used window traps, which yields large samples at low cost without destroying the wood (Siitonen 1994, Økland 
1996, Hyvärinen et al. 2006), but assesses the fauna on a larger scale than we were targeting (Hammond 1997, Ranius \& Jansson 2002, Wikars et al. 2005). We instead chose to test three methods; extracting beetles from bark that had been peeled from the wood, and two methods for rearing out beetles from wood samples. None of these methods can accurately identify which of the species emerging from a wood sample have been using it for breeding, but they give a better indication than the larger-scale sampling techniques, such as window traps (Wikars et al. 2005). As we sampled logging residues the problem of being destructive was small in this case.

The first method, to extract invertebrates from various kinds of debris using a Tullgren funnel is often used (New 1998). The debris is placed on a net in a funnel with a collection vial at the bottom. Above the funnel there may be a heat source which forces the invertebrates to move through the bottom of the debris sample and fall down to the vial. The debris can also be concentrated with a sieve so that only the fine fractions, including most of the insects, are placed in the funnel (New 1998). This method has been used (inter alia) in studies of saproxylic beetle fauna in high stumps (Jonsell et al. 2004).

To rear out beetles, wood samples are collected in the field and placed in rearing containers. The emerging insects can then be collected in at least two ways. In the first method the insects are attracted to light. The wood sample is stored in a dark box and newly reared insects are attracted to the light in a transparent vial inserted in the box, where they can be collected. This method has been used for collecting insects in logging residues (Nittérus et al. 2004) and insects in bracket fungi (Midtgaard et al. 1998, Jonsell et al. 2001, Komonen 2001). In the second method a collection vial is placed under the wood sample and relies on the majority of the insects eventually ending up at the bottom of the rearing container. This method has been used in studies of bark beetles and associated species (Hedgren \& Schroeder 2004) and for insects in aspen wood (Hammond 1997).

The aim of this study was to compare the efficiency of the three different methods of collecting saproxylic beetles from specific types of logging residues: 1) Sifting: Sifting peeled bark and ex- tracting the beetles in a Tullgren funnel. 2) Boxrearing: Rearing out beetles in dark wooden boxes and collecting them in a transparent vial (Fig. 1a). 3) Sack-rearing: Rearing out beetles in hanging cotton sacks and collecting them in the bottom of the rearing container (Fig. 1b). The efficiency of each method was measured by comparing the number of species that were collected using them. For the more frequently occurring species we also performed species-wise analyses, comparing how frequently each species was caught.

\section{Material and methods}

Samples for comparing sifting with the sack-rearing method were collected in a first sampling series, from 12 clear cuts in southern Sweden in the autumn of 2002 and the spring of 2003. Samples for comparing box-rearing with sack-rearing were collected in a second sampling series from 26 clear cuts in the same regions as the first series, in the autumn of 2003 and the spring of 2004. In the first sampling series we collected, from each site, two samples of birch (Betula spp.) and two of spruce (Picea abies) for sifting, and the same number of samples for sack-rearing. In total there were 24 samples of each tree species and sampling method. In the second series we collected samples of four tree species: birch, spruce, aspen (Populus tremulae) and oak (Quercus robur) and two diameter classes $(1-4 \mathrm{~cm}$ and 4-8 cm). Two samples for each combination of tree species and diameter class were collected from each clear cut, one to be placed in a rearing box and one in a rearing sack. However, it was not possible to find samples of all four tree species on some of the clear cuts. Therefore, the total number of samples varied between tree species and we had, for each method: 45 samples of birch, 46 of spruce, 38 of aspen and 28 of oak.

For both sampling series, half of the clear cuts were one summer old and the other half three to five years old. Each wood sample was collected from several points distributed over the clear cut. On most of the clear cuts, the fine wood is aggregated in piles laid by the harvester. The wood was then taken from at least five different piles. Only wood with intact bark was sampled because many 


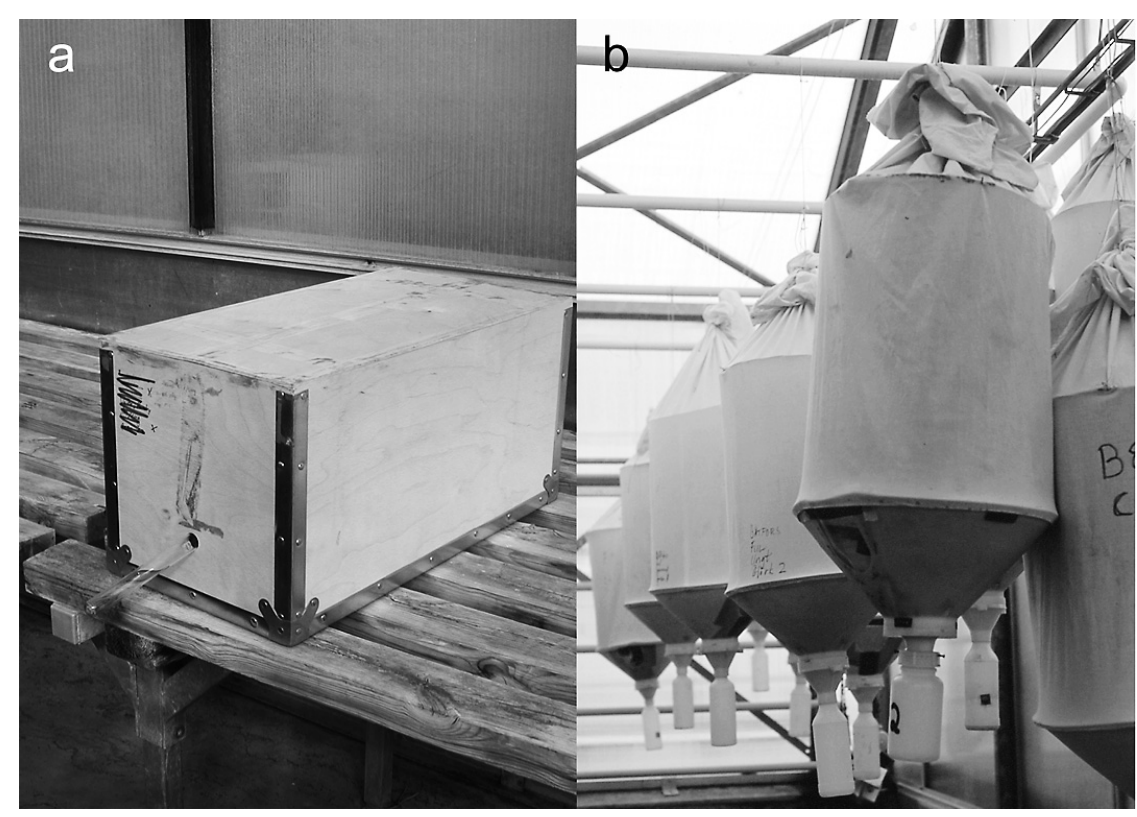

Fig. 1. The two rearing containers in the comparison. - a. Rearing box. -b. Rearing sack. saproxylic beetle species live under the bark. The diameter of the wood varied between 1 and $8 \mathrm{~cm}$. The sampling was undertaken during autumn or spring, as recommended for sieve samples (Wikars et al. 2005).

The sieve samples each consisted of $10 \mathrm{~m}$ of wood. The bark of this wood was peeled off with a knife on a large cloth. The material on the cloth was then poured into a sieve with a mesh size of about $4 \mathrm{~mm}$. After sifting, the fine material was collected in textile bags and brought to the laboratory, where insects were driven out in Tullgren funnels for at least 24 hours.

The rearing samples consisted of bunches of $50 \mathrm{~cm}$ long wood-pieces, that were brought to the laboratory where insects were reared out. Each bunch was $25-35 \mathrm{~cm}$ in diameter. In the laboratory the wood bunches were put into rearing containers (i.e. boxes or sacks), that were placed in a greenhouse at a temperature of $20^{\circ} \mathrm{C}$. There were some deviations from this temperature, especially during warm days in the summer, but all samples within the same rearing cohort experienced the same temperature regime.

The rearing boxes (Fig. 1a) were constructed from plywood. The wettest wood samples were dried for several days before closing the boxes, to avoid excessive growth of microfungi. Insects were collected in a glass vial inserted in one ga- ble. At the end of the rearing period the remains at the bottom of the wooden box were also inspected for insects, as not all insects were caught in the vials.

For rearing in sacks (Fig. 1b) the samples were first hung from the ceiling by string. Each wood bunch was then enclosed in a cotton sack, which had metal wires on the inside so that the wood did not come into contact with the sack. The insects were collected in a plastic vial attached to a plastic funnel at the bottom of the cotton sack.

All saproxylic beetles were identified to the species level by the authors, according to the nomenclature of Lundberg and Gustafsson (1995), however larvae were not identified. Scolytinae and Curculionidae are treated as separate taxa here because of the specific biology of the scolytines. All species were assigned as saproxylic or not based on Palm (1959), Hansen (1964) and Koch (1989-1992).

The frequency of each beetle species was calculated as the number of samples it was detected in by each sampling method, for each tree species separately. For species occurring in more than five samples we tested whether there were statistically significant differences $(p<0.05)$ in frequencies between sampling methods by $2 \times 2$ contingency tables with Fisher's exact test using the software Statview 5.0.1 for Mac. 
Table 1. The number of saproxylic beetle species encountered in samples collected with three different sampling methods. Numbers are shown for all species and for some selected families. The two comparisons were made with two different datasets.

\begin{tabular}{|c|c|c|c|c|}
\hline & \multicolumn{2}{|c|}{ First comparison } & \multicolumn{2}{|c|}{ Second comparison } \\
\hline & Sieve & Rearing sac & Rearing box & Rearing sac \\
\hline \multicolumn{5}{|l|}{ Birch } \\
\hline Total & 38 & 52 & 47 & 48 \\
\hline Staphylinidae & 15 & 9 & 8 & 8 \\
\hline Buprestidae & 0 & 1 & 2 & 3 \\
\hline Melyridae & 0 & 3 & 3 & 3 \\
\hline Ciidae & 9 & 9 & 7 & 7 \\
\hline Melandryidae, Anaspidae, Mordellidae & 0 & 3 & 3 & 1 \\
\hline Cerambycidae & 0 & 3 & 4 & 6 \\
\hline Curculionidae, Anthribidae & 2 & 2 & 5 & 4 \\
\hline Scolytinae & 2 & 7 & 5 & 4 \\
\hline \multicolumn{5}{|l|}{ Spruce } \\
\hline Total & 25 & 35 & 35 & 49 \\
\hline Staphylinidae & 7 & 5 & 1 & 9 \\
\hline Buprestidae & 0 & 1 & 2 & 1 \\
\hline Melyridae & 0 & 2 & 3 & 3 \\
\hline Ciidae & 5 & 8 & 7 & 8 \\
\hline Melandryidae, Anaspidae, Mordellidae & 1 & 1 & 2 & 3 \\
\hline Cerambycidae & 0 & 2 & 2 & 2 \\
\hline Curculionidae, Anthribidae & 0 & 4 & 3 & 2 \\
\hline Scolytinae & 7 & 6 & 10 & 10 \\
\hline \multicolumn{5}{|l|}{ Aspen } \\
\hline Total & - & - & 34 & 44 \\
\hline Staphylinidae & - & - & 4 & 11 \\
\hline Buprestidae & - & - & 1 & 1 \\
\hline Melyridae & - & - & 2 & 4 \\
\hline Ciidae & - & - & 5 & 6 \\
\hline Melandryidae, Anaspidae, Mordellidae & - & - & 2 & 2 \\
\hline Cerambycidae & - & - & 5 & 5 \\
\hline Curculionidae, Anthribidae & - & - & 4 & 1 \\
\hline Scolytinae & - & - & 4 & 5 \\
\hline \multicolumn{5}{|l|}{ Oak } \\
\hline Total & - & - & 38 & 48 \\
\hline Staphylinidae & - & - & 2 & 10 \\
\hline Buprestidae & - & - & 3 & 3 \\
\hline Melyridae & - & - & 3 & 3 \\
\hline Ciidae & - & - & 5 & 7 \\
\hline Melandryidae, Anaspidae, Mordellidae & - & _- & 3 & 3 \\
\hline Cerambycidae & - & - & 6 & 6 \\
\hline Curculionidae, Anthribidae & - & - & 2 & 2 \\
\hline Scolytinae & - & - & 5 & 6 \\
\hline
\end{tabular}

\section{Results}

\subsection{Sifting vs. Sack-Rearing}

In the comparison between sifting and sack-rearing, 85 saproxylic beetle species were found; 67 in birch and 43 in spruce samples. For both tree species, more beetle species were found in the sack-reared samples than in the sieved samples
(Table 1). This also applied to most beetle families, such as Buprestidae, Melyridae, Cerambycidae and Curculionidae (Table 1), but not the Staphylinidae, for which more species were found in the sieved samples. Ciids on birch and the Scolytinae in spruce samples were found in similar numbers using both of these sampling methods.

Of the species that were found in more than 
Table 2. Numbers of saproxylic beetle species found significantly $(p<0.05)$ more frequently with one of the compared sampling methods than the other, and numbers for which there was no significant difference between methods. Data are compiled from the Appendix. Significances were tested with a Fisher test in 2-way contingency tables. All species with $>5$ occurrences were tested.

\begin{tabular}{lccccccc}
\hline & \multicolumn{3}{c}{ First comparison } & & \multicolumn{3}{c}{ Second comparison } \\
\cline { 2 - 3 } \cline { 7 - 8 } Tree species & Sifting & No sign diff. & Rearing sac & & Rearing box & No sign diff. & Rearing sac \\
\hline Birch & 3 & 10 & 2 & & 0 & 18 & 6 \\
Spruce & 6 & 7 & 3 & & 0 & 15 & 1 \\
Aspen & - & - & - & & 0 & 10 & 4 \\
Oak & - & - & - & & 0 & 14 & 3 \\
\hline
\end{tabular}

five samples, several were found significantly more frequently with one of the two sampling methods (Table 2, Appendix). Most of the species that were found more frequently with sifting belonged to Staphylinidae: three out of three species on birch and four out of six on spruce. The other two species in the latter group were scolytines (bark beetles). The species that were found more frequently in rearing sacks than in sieved samples belonged to the families Buprestidae, Melyridae, Colydiidae and Scolytinae.

\subsection{Box-rearing vs. Sack-rearing}

In the comparison between the box- and sackrearing methods, 119 saproxylic species were found, of which there were 63 in birch, 58 in spruce, 55 in aspen, and 57 in oak samples. For all tree species more beetle species were encountered in rearing sacks than in rearing boxes (Table 1). Most of the total difference is due to that more staphylinid-species were found in rearing sacks than in boxes for all tree species except birch (Table 1). Small differences were also found for Ciidae, Curculionidae, and Antribidae. Numbers of ciid species were somewhat lower in rearing boxes, whereas numbers of species from the other two families were higher in the boxes than in the sacks. For other families the numbers of species found were similar for both rearing methods (Table 1).

No beetle species was found more frequently in boxes, but several species occurred more frequently in sacks (Table 2). These species were mainly staphylinids and ciids. More precisely, of the six species on birch, two were staphylinids, two ciids, and the remaining two Bitoma crenata and Platystoma albinus; the one species on spruce was a ciid; of the four species on aspen there were two staphylinids, one ciid and $B$. crenata; and the three on oak were staphylinids.

\section{Discussion}

The highest species number, counted over the whole fauna of saproxylic beetles was encountered in the rearing sacks. This method gave a higher total number of species and higher frequencies of many species compared to the other two methods. Not surprisingly, there were larger differences in species numbers and frequencies between the sifting method and rearing sacks than there were between rearing sacks and boxes. Similar differences in results have been reported between sifting and emergence traps situated in the field (Wikars et al. 2005).

The total working time needed for each sample was higher for the rearing methods than the sifting. The difference, however, was not as large as in Wikars et al. (2005) because the samples here were brought to the laboratory and consisted of fine wood, which is easier to handle. If the rearing is done in the laboratory, the time required in the field is shorter for rearing than for sifting since, in addition to collecting the wood, the bark must be peeled off and sieved. In the laboratory, on the other hand, the rearing-containers need to be arranged and to be visited about once a week for at least three months. The total time needed was therefore somewhat longer for the rearing meth- 
ods. However, as the difference in total time spent was fairly minor, we regarded the rearing methods as beneficial as more species were encountered. The shorter time needed for processing sieve samples could be logistically favourable, if laboratory space is limited or the time available for a project is short.

None of the methods require any expensive material although substantial storage space is needed over an extended period for the rearing containers, especially the sacks. As space was a limiting factor in our case, and the sacks were more difficult to buy or build we chose to use boxes when the number of samples was large. Rearing would be more complicated if large diameter-wood samples were to be studied. In such cases one could consider using emergence traps in situ, although constructing reliable traps appears to be difficult (Wikars et al. 2005, Økland 1996).

The efficiency of the methods was not uniform among systematic groups. Especially the staphylinids had different patterns from other species as there were large between-method differences in the numbers of species detected, and the rankings of the methods was almost opposite to the rankings for the other groups. For staphylinids, sifting was the most efficient method, sack-rearing was intermediate and box-rearing was the least efficient. The higher efficiency of sifting staphylinids as opposed to rearing them is not easily explained, but a similarly large difference has also been reported for rearing containers in the field (Wikars et al. 2005, Appendix). For other species the difference in efficiency seems related to the developmental stage of the beetles in the wood. For example, Ciids and Scolytines are almost always present as adults in the wood and they were collected with similar efficiency by both sifting and rearing, whereas buprestids, melyrids, melandryids, cerambycids and curculionids (except Scolytinae) are mainly present as larvae and therefore need to be reared out.

The results obtained with the two rearing methods were quite similar, although the boxes were less effective for Staphylinids and to some extent also for Ciids. These two groups consist of small species, which therefore may be lost in the rearing container. After emergence in the boxes they might go back into the wood sample and die.
This is more likely for samples that lay on the bottom of the box than for free-hanging samples. Small specimens may also be more easily lost than larger ones due to decay among the remains on the bottom of the box.

Some of the samples in the boxes were apparently too moist since considerable amounts of fungi had grown on them by the end of the rearing period, despite drying the wettest samples before closing the boxes. This was not a problem in the sacks. On the other hand, we suspected that the samples in the sacks might dry out so much that we could lose species. However, this appeared not to be the case as no species were found less frequently in the sacks. We conclude that, for larger species, the two rearing methods have similar efficacy, but the remains at the bottom of the boxes need to be examined at the end of the rearing period. As this can result in the release of dust and spores into the air, good ventilation or breathing protection would be required.

\section{Conclusion}

The best method to use for sampling saproxylic beetles depends upon the focus of the study and both the space and time available for storing and monitoring the samples. We aimed to compare beetle faunas from specific substrates and found that rearing the beetles out from the wood was the best as the wood was of small diameter and could be handled practically (see also Ranius \& Jansson 2002, Wikars et al. 2005). If smaller species are of interest it is better to use a rearing container with a collection vial at the bottom, rather than using dark boxes with light as an attractant. However, if the aim of the sampling is to focus on a specific group of beetles the ranking of methods might be different, as shown here with the Staphylinids. Whilst sifting was shown to be the least effective method it could still be useful when space or time for handling samples is limited or if the wood is coarse.

Acknowledgements. Per-Olof Hedgren gave valuable comments on the manuscript. The study was financed by the Swedish Energy Agency and the EU-project WOOD-ENMAN. 


\section{References}

Egnell, G., Liedholm, H. \& Lönnell, N. 2001: Skogsbränsle, hot eller möjlighet? vägledning till miljövänligt skogsbränsleuttag. — Skogsstyrelsen, Jönköping. $119 \mathrm{pp}$.

Grove, S.J. 2002: Saproxylic insect ecology and the sustainable management of forests. - Annual Review of Ecology and Systamatics 33: 1-23.

Hammond, J.H.E. 1997: Arthropod biodiversity from Populus coarse woody material in north-central Alberta: A review of taxa and collection methods. - The Canadian Entomologist 129: 1009-1033.

Hansen, V. 1964: Fortegnelse over Danmarks biller 1. og 2. del. (Catalogue of the Coleoptera of Denmark 1 and 2nd part). - Entomologiske Meddelelser 33: 1-507.

Hedgren, P.-O. \& Schroeder, L.M. 2004: Reproductive success of the spruce bark beetle Ips typographus (L.) and occurrence of associated species: a comparison between standing beetle-killed trees and cut trees. Forest Ecology and Management 203: 241-250.

Hyvärinen, E., Kouki, J. \& Martikainen, P. 2006: A comparison of three trapping methods used to survey forestdwelling Coleoptera. - European Journal of Entomology 103: 397-407.

Jonsell, M., Weslien, J. \& Ehnström, B. 1998: Substrate requirements of red-listed saproxylic invertebrates in Sweden. - Biodiversity and Conservation 7: 749764.

Jonsell, M., Nordlander, G. \& Ehnström, B. 2001: Substrate associations of insects breeding in fruiting bodies of wood-decaying fungi. - Ecological Bulletins 49: 173-194.

Jonsell, M., Nittérus, K. \& Stighäll, K. 2004: Saproxylic beetles in natural and man-made deciduous high stumps retained for conservation. - Biological Conservation 118: 163-173.

Koch, K. 1989-1992: Die Käfer Mitteleuropas. Ökologie. Band 1-3. - Goecke \& Evers, Krefeld. 382 pp.

Komonen, A. 2001: Structure of insect communities inhabiting old-growth forest specialist bracket fungi. Ecological Entomology 26: 63-75.
Lindhe, A., Lindelöw, Å. \& Åsenblad, N. 2005: Saproxylic beetles in standing dead wood - density in relation to substrate sun-exposure and diameter. - Biodiversity and Conservation 14: 3033-3053.

Lundberg, S. \& Gustafsson, B. 1995: Catalogus Coleopterorum Sueciae. - Naturhistoriska riksmuseet, Stockholm. 215 pp.

Midtgaard, F., Rukke, B.A. \& Sverdrup-Thygeson, A. 1998: Habitat use of the fungivorous beetles Bolitophagus reticulatus (Coleoptera: Tenebrionidae): Effects of basidiocarp size, humidity and competitors. European Journal of Entomology 95: 559-570.

New, T.R. 1998: Invertebrate surveys for conservation. Oxford University Press, Oxford. 240 pp.

Nittérus, K., Gunnarsson, B. \& Axelsson, E. 2004: Insects reared from logging residue on clear-cuts. - Entomologica Fennica 15: 53-61.

Økland, B. 1996: A comparison of three methods of trapping saproxylic beetles. - European Journal of Entomology 93: 195-209.

Palm, T. 1959: Die Holz- und Rindenkäfer der süd- und mittelschwedischen Laubbäume. - Opuscula Entomologica Supplementum 16: 1-374.

Peterken, G.F. 1996: Natural woodland. - Cambridge University Press, Cambridge. 522 pp.

Ranius, T. \& Jansson, N. 2002: A comparison of three methods to survey saproxylic beetles in hollow oaks. Biodiversity and Conservation 11: 1759-1771.

Siitonen, J. 1994: Decaying wood and saproxylic Coleoptera in two old spruce forests: a comparison based on two sampling methods. - Annales Zoologici Fennici 31: 8934195 .

Siitonen, J. 2001: Forest management, coarse woody debris and saproxylic organisms: Fennoscandian boreal forests as an example. - Ecological Bulletins 49: 1141.

Wikars, L.-O., Sahlin, E. \& Ranius, T. 2005: A comparison of three methods to estimate species richness of saproxylic beetles (Coleoptera) in logs and high stumps of Norway spruce. - The Canadian Entomologist 137: 304-324. 
Appendix. Numbers of samples with occurrences of saproxylic beetle species using different collection methods from each tree species. Beetle species are sorted systematically according to Lundberg \& Gustafsson (1995). Statistical differences between methods within each tree species were tested with Fisher's exact test in a 2-way contingency table for all beetle species that occurred in more than five samples and noted as: ${ }^{*}=p<0.05$;

${ }^{* *}=p<0.01 ;{ }^{* * *}=p<0.0001$.

\begin{tabular}{|c|c|c|c|c|c|c|c|c|c|c|c|c|}
\hline \multirow[b]{2}{*}{$\begin{array}{l}\text { Family } \\
\text { Species }\end{array}$} & \multicolumn{2}{|c|}{ Birch } & \multicolumn{2}{|c|}{ Spruce } & \multicolumn{2}{|c|}{ Aspen } & \multicolumn{2}{|c|}{ Birch } & \multicolumn{2}{|c|}{ Oak } & \multicolumn{2}{|c|}{ Spruce } \\
\hline & $\begin{array}{r}\text { Sift } \\
n=24\end{array}$ & $\begin{array}{l}\text { Sack } \\
n=24\end{array}$ & $\begin{array}{r}\text { Sift } \\
n=24\end{array}$ & $\begin{array}{l}\text { Sack } \\
n=24\end{array}$ & $\begin{array}{r}\text { Box } \\
n=38\end{array}$ & $\begin{array}{l}\text { Sack } \\
n=38\end{array}$ & $\begin{array}{r}\text { Box } \\
n=45\end{array}$ & $\begin{array}{l}\text { Sack } \\
n=45\end{array}$ & $\begin{array}{r}\text { Box } \\
n=28\end{array}$ & $\begin{array}{l}\text { Sack } \\
n=28\end{array}$ & $\begin{array}{r}\text { Box } \\
n=46\end{array}$ & $\begin{array}{l}\text { Sack } \\
n=46\end{array}$ \\
\hline
\end{tabular}

\section{Scydmaenidae}

Microscydmus nanus

Silphidae

Phosphuga atrata

Staphylinidae

Gabrius splendidulus

Gabrius expectatus

Quedius xanthopus

Bibloporus bicolor

Euplectus piceus

Tyrus mucronatus

Acrulia inflata

Phloeonomus sjoebergi

Phloeocharis subtilissima

Sepedophilus littoreus

Phloeopara corticalis

Dadobia immersa

Dinaraea aequata

Dinaraea linearis

Leptusa pulchella

Leptusa fumida

Leptusa ruficollis

Anomagnathus cuspidatus

Homalota plana

Cyphea curtula

Placusa depressa

Scarabaeidae

Trichius fasciatus

Lucanidae

Platycerus caprea

Lycidae

Lygistopterus sanguineus

Elateridae

Denticollis linearis

Denticollis borealis

Melanotus spp.

Eucnemidae

Microrhagus pygmaeus

Buprestidae

Anthaxia quadripunctata

Anthaxia godeti

Chrysobothris affinis

Agrilus angustulus

Agrilus sulcicollis

Agrilus betuleti

Agrilus viridis

Agrilus suvorovi

Dermestidae

Anthrenus museorum

Anobiidae

Ptinus fur

\begin{tabular}{|c|c|c|c|c|c|c|c|c|c|c|c|}
\hline 1 & - & - & - & - & - & - & - & - & - & - & - \\
\hline 1 & - & - & - & - & - & - & - & 1 & - & - & - \\
\hline 1 & - & - & - & - & - & - & - & - & - & - & - \\
\hline 1 & - & - & - & 1 & - & - & - & - & - & - & - \\
\hline- & - & 1 & - & - & - & - & - & - & - & - & - \\
\hline 1 & 1 & - & - & - & - & - & - & - & 1 & - & - \\
\hline 1 & - & - & - & - & - & - & - & - & - & - & - \\
\hline 2 & - & - & - & - & - & - & 2 & 1 & 2 & - & 1 \\
\hline 5 & - & - & - & - & 2 & 1 & - & - & - & - & - \\
\hline- & - & 1 & - & - & - & - & - & - & - & - & 1 \\
\hline $9^{*}$ & 3 & $9^{*}$ & 2 & 3 & 8 & 2 & $11^{*}$ & - & $8^{* *}$ & 2 & 3 \\
\hline - & - & - & - & - & - & 1 & - & - & - & - & - \\
\hline 2 & 2 & - & - & - & 4 & - & 4 & - & 2 & - & 3 \\
\hline $14^{*}$ & 6 & $11^{*}$ & 3 & 1 & 4 & 5 & 9 & - & $6^{*}$ & - & 4 \\
\hline $9^{\star \star \star *}$ & - & - & 1 & - & 1 & 1 & 3 & - & 3 & - & 1 \\
\hline 1 & - & - & - & - & - & - & - & - & - & - & - \\
\hline 7 & 3 & 5 & - & - & 1 & - & - & - & 1 & - & - \\
\hline 7 & 3 & $8^{* *}$ & 1 & - & $8^{* *}$ & 1 & $15^{\star * *}$ & - & $7^{*}$ & - & 4 \\
\hline 7 & 2 & $9^{*}$ & 3 & - & 2 & 1 & 2 & - & 3 & - & 4 \\
\hline 2 & 1 & - & - & 2 & $12^{* *}$ & 1 & 6 & 1 & 3 & - & 1 \\
\hline - & - & - & - & - & 2 & - & - & - & - & - & - \\
\hline - & - & - & - & - & 1 & - & - & - & - & - & - \\
\hline- & 1 & - & - & - & - & - & - & - & - & - & - \\
\hline- & 1 & - & - & - & - & - & - & - & - & - & - \\
\hline- & - & - & - & - & - & - & 1 & - & - & - & - \\
\hline 6 & 5 & 1 & - & - & - & 2 & 1 & - & - & 2 & 2 \\
\hline 1 & 1 & _- & - & - & _- & - & - & - & - & - & - \\
\hline - & - & - & - & - & - & 1 & - & - & - & - & - \\
\hline- & 1 & - & - & - & - & - & - & - & - & - & - \\
\hline- & - & - & - & - & 1 & - & - & - & - & - & - \\
\hline - & - & - & $8^{* *}$ & - & - & - & - & - & - & 1 & 3 \\
\hline - & - & - & - & - & - & - & - & - & - & 1 & - \\
\hline - & - & - & - & - & - & - & 2 & 4 & 5 & - & - \\
\hline - & - & - & - & - & - & - & - & 8 & 11 & - & - \\
\hline - & - & - & - & - & - & - & - & 5 & 5 & - & - \\
\hline - & $7^{* *}$ & - & - & - & - & 10 & 6 & - & - & - & - \\
\hline - & - & - & - & - & - & 4 & 2 & - & - & - & - \\
\hline- & - & - & - & 7 & 8 & - & - & - & - & - & - \\
\hline- & 1 & - & - & - & - & - & - & - & - & - & - \\
\hline - & - & - & 2 & - & - & - & - & - & - & - & _ \\
\hline
\end{tabular}


Ernobius abietis

Stegobium paniceum

Trogossitidae

Nemozoma elongatum

Cleridae

Thanasimus formicarius

Melyridae

Dasytes niger

Dasytes cyaneus

Dasytes plumbeus

Malachius bipustulatus

Nitidulidae

Epuraea pygmaea

Epuraea rufomarginata

Glischrochilus quadripunctatus

Rhizophagidae

Rhizophagus dispar

Rhizophagus bipustulatus

Laemoploeidae

Laemophloeus muticus

Cryptolestes alternans

Erotylidae

Dacne bipustulata

Cerylonidae

Cerylon fagi

Cerylon histeroides

Cerylon ferrugineum

Cerylon deplanatum

Corylophidae

Orthoperus punctatus

Orthoperus mundus

Corticariidae

Latridius hirtus

Latridius minutus

Enicmus transversus

Dienerella elongata

Aridius nodifer

Corticaria rubripes

Ciidae

Cis comptus

Cis hispidus

Cis micans

Cis boleti

Cis rugulosus

Cis punctulatus

Orthocis alni

Orthocis vestitus

Orthocis festivus

Sulcacis affinis

Octotemnus glabriculus

Colydiidae

Synchita humeralis

Bitoma crenata

Mycetophagidae

Litargus connexus

Pyrochroidae

Pyrochroa coccinea

Schizotus pectinicornis

Salpingidae

Salpingus planirostris

Salpingus ruficollis

Aderidae

Anidorus nigrinus

$\begin{array}{llllllllllll}- & 5 & - & 9^{* *} & 2 & 3 & 3 & 4 & 2 & 1 & 3 & 3 \\ - & 3 & - & 1 & - & 2 & 3 & 3 & 2 & 4 & 4 & 2 \\ - & 1 & - & - & 2 & 1 & 1 & 1 & 1 & 2 & 6 & 4 \\ - & - & - & - & - & 1 & - & - & - & - & - & -\end{array}$

$\begin{array}{llllllllllll}- & - & - & - & - & - & - & - & - & - & - & 1 \\ - & - & - & - & - & - & 1 & 1 & 1 & 1 & - & - \\ - & - & - & - & - & - & - & - & 1 & - & -\end{array}$

$\begin{array}{llllllllllll}1 & - & - & - & - & - & - & 2 & - & - & - & 1 \\ - & - & - & - & - & 2 & - & 1 & - & - & - & - \\ - & 1 & - & - & - & 1 & - & - & - & 1 & - & - \\ - & 2 & - & - & - & - & 1 & - & - & - & - & - \\ - & - & - & - & - & 1 & - & - & - & - & - & -\end{array}$

$\begin{array}{llllllllllll}- & - & - & - & - & - & 1 & - & - & - & - & - \\ - & - & - & - & - & - & - & - & 1 & - & - & - \\ - & - & - & - & - & 1 & - & - & - & - & - & - \\ - & 2 & - & - & 1 & - & - & 1 & - & - & - & 1 \\ - & - & - & 1 & - & - & - & - & - & - & - & - \\ - & - & - & - & 1 & - & 2 & - & 1 & - & 1 & - \\ 2 & - & - & - & 1 & - & - & - & - & - & - & -\end{array}$

$\begin{array}{rrrrrrrrrrrr}1 & 2 & - & - & - & - & 1 & - & - & - & - & - \\ 13 & 14 & 1 & 4 & 6 & 12 & 4 & 13^{*} & 2 & 4 & 1 & 13^{* * *} \\ 1 & 2 & - & 2 & - & 2 & 1 & 4 & - & - & 2 & 1 \\ 5 & 11 & - & 2 & 2 & 9^{*} & 5 & 8 & 1 & 3 & 2 & 3 \\ - & - & - & - & - & - & - & - & - & 2 & - & - \\ - & 1 & 6 & 6 & - & - & - & - & - & - & 4 & 5 \\ 1 & 3 & 3 & 7 & 1 & 3 & 2 & 8 & 1 & 2 & 1 & 7 \\ 1 & - & - & - & - & - & - & - & - & - & - & - \\ 1 & 3 & 2 & 1 & - & - & - & 6^{*} & 2 & 2 & - & 3 \\ 10 & 15 & 1 & 5 & 4 & 10 & 8 & 15 & 6 & 5 & 3 & 6 \\ 7 & 12 & - & 2 & 5 & 6 & 3 & 9 & - & 4 & 1 & 2\end{array}$

$\begin{array}{llllllllllll}- & 6^{*} & - & - & 1 & - & 4 & 6 & - & - & - & - \\ 6 & 3 & - & - & 1 & 9^{*} & - & 13^{* * *} & 1 & 7 & - & 4\end{array}$

$\begin{array}{llllllllllll}2 & 1 & - & 1 & - & - & - & 5 & - & - & -\end{array}$

$\begin{array}{rrrrrrrrrrr}- & - & - & - & - & - & - & - & - & 1 & - \\ 13 & 16 & - & - & 8 & 5 & 10 & 14 & 5 & 3 & -\end{array}$

$\begin{array}{llllllllllll}- & 2 & - & 1 & - & 1 & - & - & - & - & - & - \\ - & - & - & - & - & - & - & 2 & - & - & - & 1\end{array}$ 


\section{Tenebrionidae}

Corticeus linearis

\section{Scraptiidae}

Anaspis bohemica

Anaspis thoracica

Anaspis rufilabris

Anaspis flava

Mordellidae

Tomoxia bucephala

Mordella holomelaena

Curtimorda maculosa

Melandryidae

Orchesia undulata

Abdera triguttata

Cerambycidae

Rhagium mordax

Leptura quadrifasciata

Leptura melanura

Molorchus minor

Pyrrhidium sanguineum

Xylotrechus rusticus

Clytus arietis

Plagionotus arcuatus

Pogonocherus hispidulus

Pogonocherus fasciculatus

Acanthoderes clavipes

Leiopus nebulosus

Leiopus punctulatus

Saperda scalaris

Saperda perforata

\section{Anthribidae}

Allandrus undulatus

Dissoleucas niveirostris

Platystomus albinus

Curculionidae

Rhyncolus ater

Magdalis violacea

Magdalis carbonaria

Magdalis cerasi

Pissodes pini

Trachodes hispidus

Scolytinae

Hylurgops palliatus

Xylechinus pilosus

Phloeotribus spinulosus

Scolytus ratzeburgi

Scolytus intricatus

Pityogenes chalcographus

Pityogenes quadridens

Pityogenes bidentatus

Orthotomicus suturalis

Ips typographus

Dryocoetes autographus

Crypturgus spp.

Trypodendron domesticum

Trypodendron lineatum

Xyleborus dispar

Xyleborinus saxesenii

Trypophloeus bispinulus

Trypophloeus grothii

Pityophthorus micrographus

\begin{tabular}{|c|c|c|c|c|c|c|c|c|c|c|c|}
\hline- & - & 2 & 2 & - & - & - & - & - & - & 5 & 12 \\
\hline- & 1 & - & - & - & - & - & - & - & - & 1 & 1 \\
\hline- & - & - & - & - & - & - & - & 1 & - & - & - \\
\hline- & - & - & - & 1 & - & - & - & - & 2 & - & 1 \\
\hline- & - & - & 1 & - & - & - & - & - & - & - & - \\
\hline- & - & - & - & - & - & 1 & - & - & - & - & - \\
\hline- & 1 & - & - & - & 1 & 7 & 5 & 2 & 1 & - & - \\
\hline- & - & - & - & - & - & - & - & - & - & 1 & - \\
\hline- & - & 1 & - & 1 & 1 & 2 & - & 5 & 2 & - & 1 \\
\hline- & 1 & - & - & - & - & - & - & - & - & - & - \\
\hline- & 1 & - & - & 1 & - & - & - & - & 2 & - & - \\
\hline- & - & - & - & - & 1 & 2 & 2 & - & - & - & - \\
\hline- & - & - & - & - & - & - & 1 & - & - & - & - \\
\hline- & - & - & 3 & - & - & - & - & - & - & 2 & 5 \\
\hline- & - & - & - & - & - & - & - & 1 & - & - & - \\
\hline- & - & - & - & 2 & 5 & - & - & - & - & - & - \\
\hline- & - & - & - & - & - & 1 & 1 & 1 & 1 & - & - \\
\hline- & - & - & - & - & - & - & - & 3 & 3 & - & - \\
\hline- & - & - & - & - & - & - & - & 1 & 1 & - & - \\
\hline- & - & - & 2 & - & - & - & 1 & - & - & 6 & 9 \\
\hline- & 1 & - & - & 1 & 1 & 4 & 4 & - & - & - & - \\
\hline- & - & - & - & - & - & - & - & 5 & 2 & - & - \\
\hline- & - & - & - & 1 & 1 & - & - & - & - & - & - \\
\hline- & 3 & - & - & - & - & 2 & 4 & 2 & 1 & - & - \\
\hline- & - & - & - & 1 & 1 & - & - & - & - & - & - \\
\hline- & 2 & - & - & 3 & 4 & 2 & 2 & - & - & 1 & - \\
\hline- & - & - & - & 1 & - & 1 & - & - & - & - & - \\
\hline 1 & - & - & 1 & 1 & - & - & $7^{*}$ & - & 2 & - & - \\
\hline- & - & - & 2 & - & - & - & 1 & - & 1 & - & 1 \\
\hline- & - & - & 5 & - & - & 1 & - & - & - & 3 & 5 \\
\hline- & 5 & - & 1 & - & - & 8 & 9 & - & - & - & - \\
\hline- & - & - & - & - & - & - & - & 1 & - & - & - \\
\hline 1 & - & - & - & - & - & - & - & - & - & 1 & - \\
\hline- & - & - & - & 1 & - & 3 & - & 3 & - & - & - \\
\hline- & - & 3 & - & - & - & - & - & - & - & - & 1 \\
\hline- & - & - & - & - & - & - & - & - & - & 2 & 1 \\
\hline- & - & - & - & - & - & - & - & - & - & 2 & - \\
\hline- & 1 & - & - & - & - & - & - & - & - & - & - \\
\hline- & - & - & - & - & - & - & - & 4 & 7 & - & - \\
\hline 11 & 5 & 35 & 35 & 10 & 11 & 12 & 15 & 7 & 6 & 35 & 38 \\
\hline- & - & 4 & 1 & - & - & - & - & - & - & 1 & 2 \\
\hline- & - & $10^{*}$ & 3 & - & - & - & - & - & - & 8 & 4 \\
\hline- & - & - & - & - & - & - & 1 & - & - & - & 1 \\
\hline- & - & - & - & - & - & - & - & - & - & 1 & - \\
\hline- & 2 & $12^{*}$ & 5 & 1 & 1 & 2 & - & 1 & 1 & 4 & 1 \\
\hline- & 3 & 3 & $11^{*}$ & - & - & 1 & 2 & - & 1 & 8 & 11 \\
\hline 1 & 1 & - & - & - & - & - & - & - & - & - & - \\
\hline- & - & - & - & - & - & - & - & - & - & - & 1 \\
\hline- & 1 & - & - & 2 & 1 & 1 & 2 & 3 & 3 & 2 & - \\
\hline- & - & - & - & - & - & - & - & 1 & 1 & - & - \\
\hline- & - & - & - & - & 1 & - & - & - & - & - & - \\
\hline- & - & - & - & 4 & 4 & - & - & - & - & - & - \\
\hline 1 & 13 & 20 & - & - & 1 & - & - & - & 11 & 13 & - \\
\hline
\end{tabular}

